\title{
Receptor tyrosine kinase signaling regulates replication of the peste des petits ruminants virus
}

\author{
K. CHAUDHARY ${ }^{\text {, }}$ K. K. CHAUBEY ${ }^{\mathrm{a}}$, S. V. SINGH, N. KUMAR ${ }^{*}$
}

Virology Laboratory, Division of Animal Health, Central Institute for Research on Goats, Indian Council of Agricultural Research, Makhdoom, Uttar Pradesh 28112, India

Received June 3, 2014; accepted February 13, 2015

\begin{abstract}
Summary. - In this study, we found out that blocking the receptor tyrosine kinase (RTK) signaling in Vero cells by tryphostin AG879 impairs the in vitro replication of the peste des petits ruminants virus (PPRV). A reduced virus replication in Trk1-knockdown (siRNA) Vero cells confirmed the essential role of RTK in the virus replication, in particular a specific regulation of viral RNA synthesis. These data represent the first evidence that the RTK signaling regulates replication of a morbillivirus.
\end{abstract}

Keywords: PPR virus; receptor tyrosine kinase; RNA synthesis

\section{Introduction}

PPR is an acute, highly contagious and fatal disease of small ruminants, characterized by pyrexia, ocular and nasal discharge, erosive lesion on different mucous membranes (particularly in the mouth), enteritis and pneumonia, which ultimately results in death (Shaila et al., 1989). It leads to loss of production and high mortality (up to 90\%) in small ruminants, therefore increases poverty in some of the poorest parts of the world where it is currently endemic: Africa, the Middle East and Western and Southern Asia (Kumar et al., 2014). PPR is caused by a morbillivirus that belongs to the family Paramyxoviridae (Gibbs et al., 1979).

For the control of PPR, a live attenuated cell culture vaccine is commercially available (Kumar et al., 2014). PPRV vaccine is heat sensitive, a serious drawback for the efficient use of the live attenuated vaccine in the endemic areas with hot climate where it is difficult to maintain the cold chain to

*Corresponding author. E-mail: naveenkumar.icar@gmail.com; phone: +91-8881056623. ${ }^{a}$ Equal contribution.

Abbreviations: $\mathrm{PPRV}=$ Peste des petits ruminants virus; $\mathrm{RTK}=$ receptor tyrosine kinase; shRNA = short hairpin RNA; siRNA = small interfering RNA; hpt = hours post-transfection; hpi = hours postinfection; CIRG $=$ Central Institute for Research on Goats ensure the potency of the vaccine (Kumar et al., 2014). To minimize the impact of the disease, controlling the spread of virus is of utmost importance. The vaccine can not provide instantaneous protection; therefore, antiviral compounds should be developed.

RTK are group of growth factor receptors that, upon ligand binding, undergoes autophosphorylation at Tyr residue. These phosphorylated tyrosines then recruit $\mathrm{Srchomology-2}$ (SH2) and phosphotyrosine-binding (PTB) domain-containing proteins that activate or link to downstream signaling pathways (Mayer, 2012). There are 58 known RTKs, which form 20 subfamilies (Lemmon and Schlessinger, 2010). All RTKs have a similar structure; a ligand binding domains in the extracellular region, a single transmembrane helix, and a cytoplasmic region containing protein tyrosine kinase (TK) domain and an additional carboxy (C-) terminal and juxtamembrane regulatory regions (Lemmon and Schlessinger, 2010). The RTKs have been extensively used as target for development of anticancer therapeutics (Hopfner et al., 2006). Recent studies have also suggested that the RTK signaling regulates replication of influenza and some other viruses (Eierhoff et al., 2010; He et al., 2010; Inubushi et al., 2008; Kumar et al., 2011a,b; Stantchev et al., 2007). We therefore hypothesized whether Trk1 (RTK) regulates PPR replication so that it can be used as a target to develop antiviral therapeutics against PPRV. 


\section{Materials and Methods}

Virus. PPRV/Shahjadpur/2013 maintained at Central Institute of Research on Goats (CIRG) was used and has been previously described GenBank Acc. No. KP745466. The virus was amplified in Vero cells and titrated by plaque assay (Kumar et al., 2013).

Cell and reagents. Vero cells have been maintained at CIRG. Tryphostin AG879 was procured from Sigma, USA. Trk1-specific siRNA expressing plasmid, psiRNA-hH1Trk1 and luciferase-specific siRNA (negative control) expressing plasmid, psiRNA-hH1Luc were generated by our group and have been previously described (Kumar et al., 2011a).

Cell viability assay. The cytotoxic concentration of AG879 was determined by a previously described MTT assay (Khandelwal et al., 2014). Briefly, Vero cells were grown in DMEM (Sigma, USA) supplemented with 10\% FBS (Sigma, USA) and antibiotics and incubated with increasing concentrations (up to $40 \mu \mathrm{mol} / \mathrm{l}$ ) of AG879 or DMSO (control) for $72 \mathrm{hr}$. An amount of $20 \mu \mathrm{l}$ of freshly made $5 \mathrm{mg} / \mathrm{ml}$ MTT solution was added to each well, and cells were incubated at $37^{\circ} \mathrm{C}$ for $5 \mathrm{hr}$. After removal of the medium, $200 \mu \mathrm{l}$ of DMSO was added to each well to dissolve the purple formazan product. Absorbance of MTT signals was measured at $\mathrm{A}_{550}$.

In vitro efficacy of AG879 against PPRV. The in vitro efficacy of AG879 against PPRV was determined as follows: confluent monolayers of Vero cells (12 well plates) were infected with PPRV at MOI of 1 for $1 \mathrm{hr}$, washed three times by PBS and grown in DMEM in presence of $0.04-5 \mu \mathrm{mol} / \mathrm{l}$ AG879 or equivalent volume of DMSO (control). The infectious virus released in the supernatants at $24 \mathrm{hrs}$ post-infecion (hpi) was titrated by plaque assay formation.

Real-time RT-PCR assay for viral RNA synthesis. Vero cells were infected with PPRV at an MOI of 5 for $1 \mathrm{hr}$ followed by washing 6 times with PBS and addition of fresh DMEM containing $5 \mu \mathrm{mol} / \mathrm{l}$ AG879 or equivalent volume of control. The cell lysates were prepared at 5 hpi to isolate the total RNA using TRI Reagent according to instructions of manufacturer (Sigma, Germany). The viral and cellular mRNA were quantified by quantitative real-time RT-PCR as follows: the RNA was cleared of possible DNA contamination by incubation for $45 \mathrm{~min}$ at $37^{\circ} \mathrm{C}$ and $80^{\circ} \mathrm{C}$ for $20 \mathrm{~min}$ with DNAse I followed by reverse transcription as described before (Kumar et al., 2013). Real-time RT-PCR was carried out with a $20 \mu \mathrm{l}$ reaction mixture containing gene specific primers and SYBR Green DNA dye (Promega, USA). The primers for amplification of mRNA of the PPRV N gene have been described previously (Kumar et al., 2013). $\beta$-actin was used as a house keeping control gene and was amplified using forward primer: 5'-CCC CAG CCA TGT ACG TTG CTA TCC-3' and reverse primer: 5'-GCC TCA GGG CAG CGG AAC CGC TCA-3'). For PCR amplification of both PPRV N and $\beta$-actin mRNA, following thermocycler conditions were used: an initial denaturation of $95^{\circ} \mathrm{C}$ for $5 \mathrm{~min}$ followed by 40 cycles of $95^{\circ} \mathrm{C}$ for $30 \mathrm{sec}, 52^{\circ} \mathrm{C}$ for $30 \mathrm{sec}$, and $72^{\circ} \mathrm{C}$ for $30 \mathrm{sec}$ and a final extension step of $72^{\circ} \mathrm{C}$ for $10 \mathrm{~min}$.

siRNA knockdown of Trk1. 50\% confluent monolayers of Vero cells, in triplicates, in 6 well plates, were either transfected with $2 \mu \mathrm{g}$ of Trk1 siRNA expressing plasmids (psiRNAhH1-Trk1) or with $2 \mu \mathrm{g}$ of negative control siRNA expressing plasmid (psiRNAhH1-Luc) using Escort IV transfection reagent according to the instruction of the manufacturer (Sigma, USA). The cell lysates were prepared at $72 \mathrm{hr}$ post-transfection (hpt) and quantification of the Trk1 mRNA expression in control and shRNA-treated cells was performed by quantitative real-time RT-PCR, using following primers: forward primer-5'-CAGTGACCTCAACAGGAAGAAC-3' and reverse primer-5'CATTTGTTGAGCACAAGGAGC-3'. $\beta$-actin was used as a house keeping control gene for normalization purpose. The thermocycler conditions were similar as described above for realtime RT-PCR assay for viral RNA synthesis.

Statistical analysis. Pairwise statistical comparisons were performed using Student's t test.

\section{Results}

\section{Cytotoxicity and virucidal activity of AG879}

The RTK signaling was disrupted using a known RTK inhibitor, tryphostin AG879. The cytotoxic concentration of AG879 was determined by MTT assay. As shown in Fig. 1, no cytotoxicity was observed even after $72 \mathrm{hr}$ of incubation of Vero cells with AG879 at $5 \mu \mathrm{mol} / \mathrm{l}$. However, a significant loss of viability was observed at $>5 \mu \mathrm{mol} / \mathrm{l}$. Therefore we have decided to use $5 \mu \mathrm{mol} / \mathrm{l}$ of AG879 in subsequent experiments.

In order to demonstrate whether the inhibitory effect of AG879 on PPRV replication is partially due to inactivation of the extracellular virus (virucidal activity), 3-fold serial dilutions of AG879 or equivalent volume of control were incubated with PPRV at $37^{\circ} \mathrm{C}$ for $1.5 \mathrm{hr}$ and then titrated on Vero cells by plaque formation. No significant inactivation of the PPRV was observed even at $81 \mu \mathrm{mol} / \mathrm{l}$ of AG879 (Fig. 2) suggesting AG879 has no virucidal effect on cell free virion.

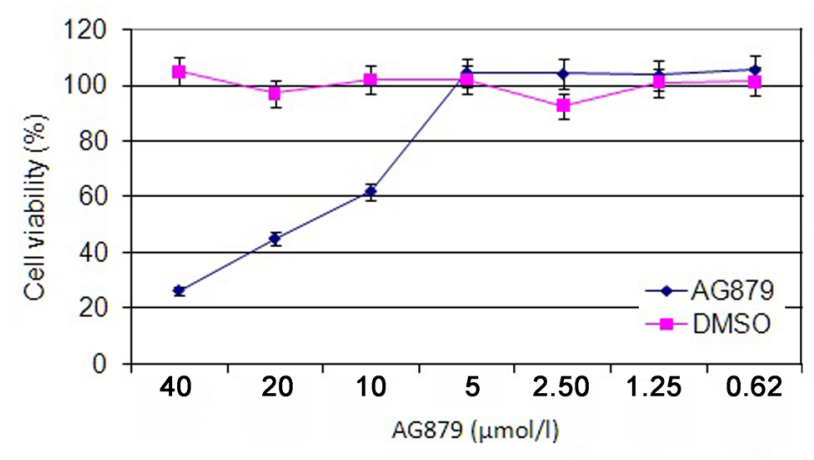

Fig. 1

Cytotoxicity of AG879

Vero cells in microplate wells were treated with $0.62-40 \mu \mathrm{mol} / \mathrm{l}$ inhibitor or DMSO for $72 \mathrm{hr}$ and then assayed for viability. 


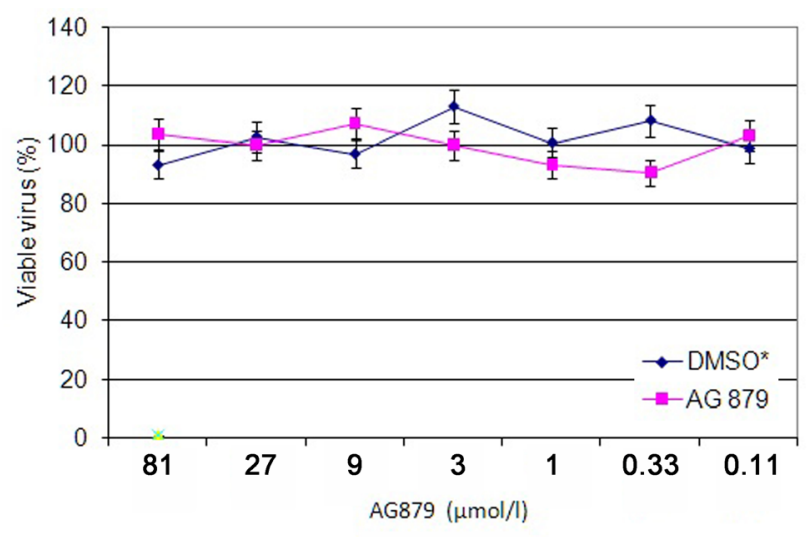

Fig. 2

Virucidal activity of AG879

The virus $\left(\sim 10^{6} \mathrm{PFU}\right)$ was incubated with either serial 3-fold dilutions $(0.11-81 \mu \mathrm{mol} / \mathrm{l})$ of AG879 or DMSO for $1.5 \mathrm{hr}$ at $37^{\circ} \mathrm{C}$ and then titrated for infectious virus.

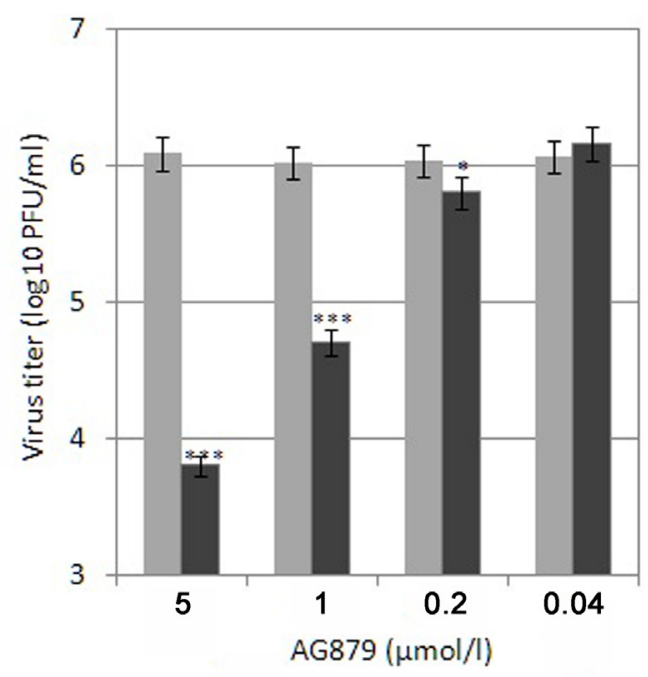

Fig. 3

Inhibition of virus replication with AG879

Vero cells were infected with the PPRV at MOI of 1 for $1 \mathrm{hr}$, washed with PBS, and refed with fresh DMEM containing either 0.04-5 $\mu \mathrm{mol} / \mathrm{l}$ AG879 or DMSO for $24 \mathrm{hr}$ and titrated for infectious virus. ${ }^{*}$ and ${ }^{* * *}$ represent statistical significance at $\mathrm{P}<0.05$ and $\mathrm{P}<0.001$, respectively.

Inhibition of virus replication and viral RNA synthesis by AG879

The in vitro efficacy of AG879 against PPRV was determined in Vero cells. As shown in Fig. 3, at a non-cytotoxic concentration $(5 \mu \mathrm{mol} / \mathrm{l})$, as compared to control-treated cells, a significant reduction in viral titers was observed in AG879-treated cells suggesting that RTK supports PPRV replication.

Next, we determined the specific steps of PPRV affected by AG879. PPRV life cycle is 6-8 hr in cultured cells (Kumar

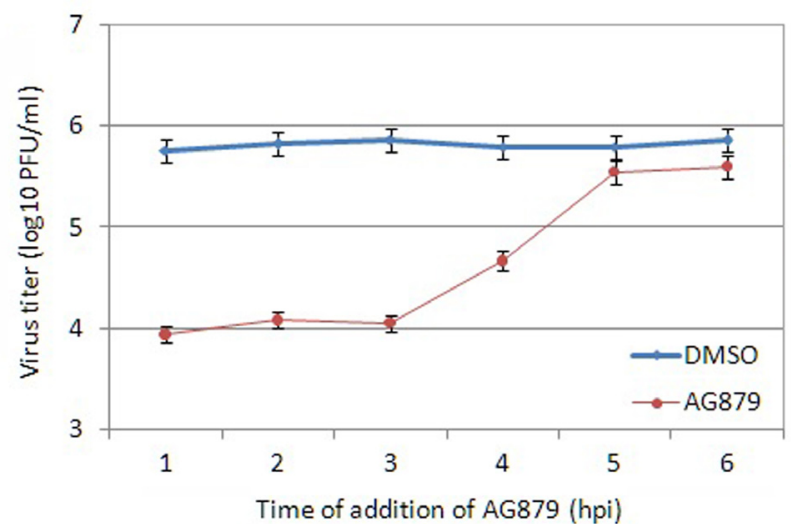

Fig. 4

Time-course of the inhibitory effect of AG879

Vero cells were infected with the PPRV at MOI of 10 for $1 \mathrm{hr}$ at $37^{\circ} \mathrm{C}$, washed with PBS and refed with DMEM. The inhibitor was applied at indicated time points and $10 \mathrm{hpi}$ the infectious virus was titered.

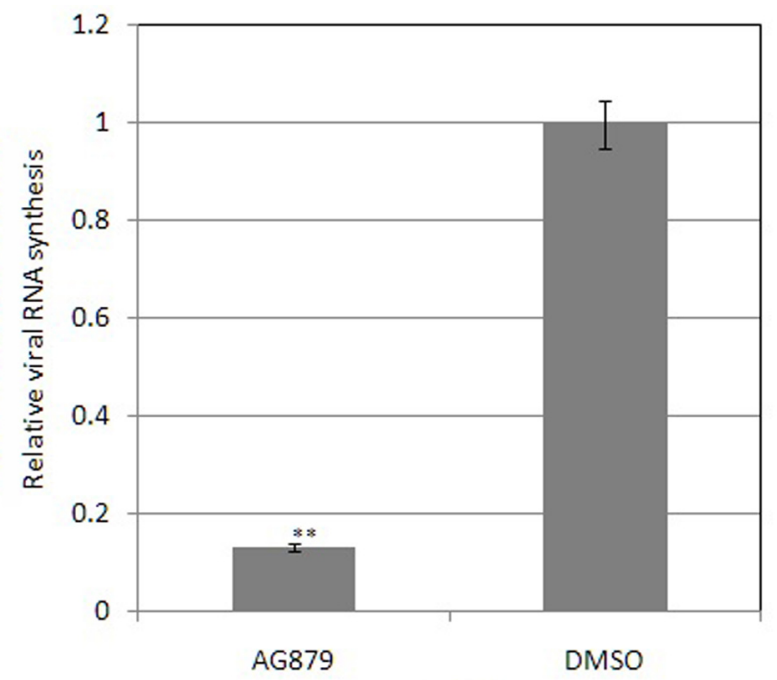

Fig. 5

Inhibition of viral RNA synthesis by AG879

Vero cells were infected with PPRV at MOI of 5 for $1 \mathrm{hr}$, washed with PBS and refed with DMEM and $3 \mathrm{hr}$ later the inhibitor or DMSO were applied. Viral RNA was assayed 5 hpi. $\beta$-actin was used as a house keeping control gene for normalization. ${ }^{* *}$ represent statistical significance at $\mathrm{P}<0.01$.

et al., 2013). Primarily, a time course assay was performed to evaluate the dynamics of the PPRV replication in presence of AG879. The inhibitor was applied at different time points following infection and the infectious virus released in to the supernatant $10 \mathrm{hpi}$ was titrated by plaque formation. As indicated in Fig. 4, as compared to the control, AG879 inhibited PPRV replication almost at a similar level whether it was applied $1 \mathrm{hpi}, 2 \mathrm{hpi}$ or $3 \mathrm{hpi}$. These results suggest that early steps such as attachment, entry and uncoating which are believed to occur within the first few hours of infection 


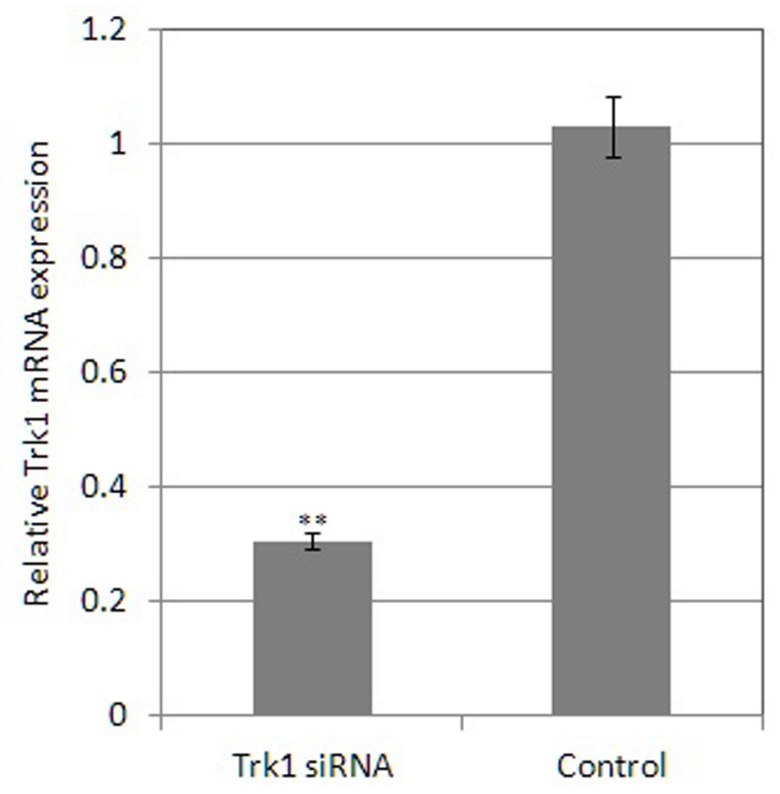

Fig. 6

Knockdown of Trk1 using plasmid expressing Trk1 siRNA Vero cells were transfected with plasmid psiRNA-hH1Trk1 expressing Trk1specific siRNA or plasmid psiRNA-hH1Luc expressing luciferase-specific siRNA (negative control) and $72 \mathrm{hpt}$, assayed for Trk1 mRNA. $\beta$-actin was used as a control house keeping gene for normalization. ${ }^{\star *}$ represents statistical significance at $\mathrm{P}<0.01$.

are unlikely to be affected. However, there was a significant rise in viral titers in AG879-treated cells, when the inhibitor was applied $4 \mathrm{hpi}$, a time point around which RNA synthesis is believed to occur (Fig. 4). Further, no significant difference in the viral titers (compared to control) were observed when the inhibitor was applied 5 hpi and 6 hpi suggesting AG879 does not inhibit later stages of PPRV replication (Fig. 4). Taken together, it was concluded from the time-course experiment that neither the early nor the late steps of PPRV life cycle are affected by AG879 and hence it was speculated that the RNA synthesis, which is believed to occur around 3-4 hpi (middle step), is most likely to be affected. As shown in Fig. 5, as compared to control-treated cells, a significant reduction in viral RNA was observed in AG879-treated cells suggesting AG879 inhibits PPRV RNA synthesis.

\section{Role of RTK in PPRV replication}

Small interfering RNA (siRNA) or short interfering RNA are a class of double-stranded RNA molecules, 20-25 base pairs in length that interfere with the expression of specific genes with complementary nucleotide sequences (Whitehead et al., 2009). In order to further confirm whether the inhibitory effect of AG879 on PPRV replication is really due to the action on its target molecule (RTK) and not due to off-target effects, a shRNA knockdown experiment was performed.

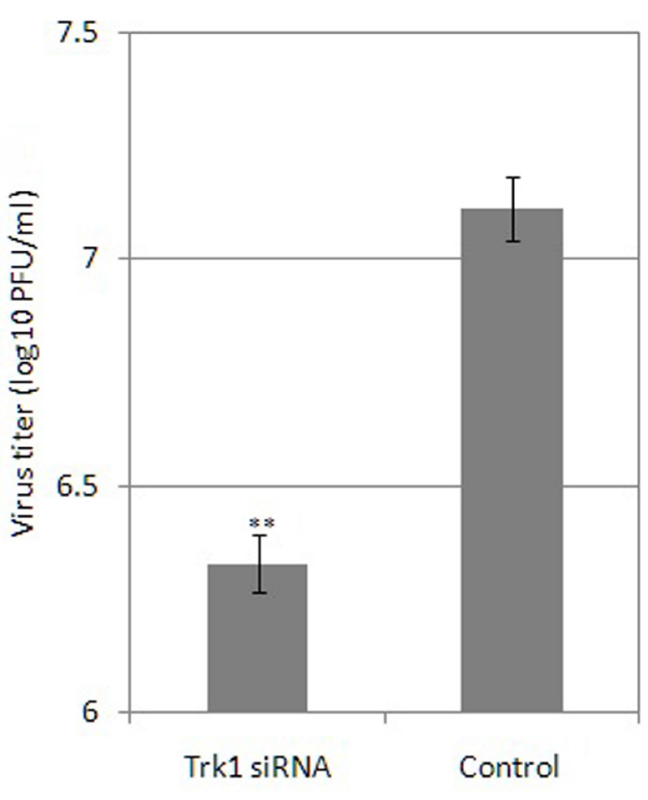

Fig. 7

Inhibition of PPRV replication by Trk1 knockdown Vero cells were transfected with plasmid psiRNA-hH1Trk1 expressing Trk1-specific siRNA or plasmid psiRNA-hH1Luc expressing luciferasespecific siRNA (negative control), $72 \mathrm{hr}$ later infected with PPRV at MOI of 10 and at $10 \mathrm{hpi}$, were titered for infectious virus. $\beta$-actin was used as a control house keeping gene for normalization. ${ }^{*}$ represents statistical significance at $\mathrm{P}<0.01$.

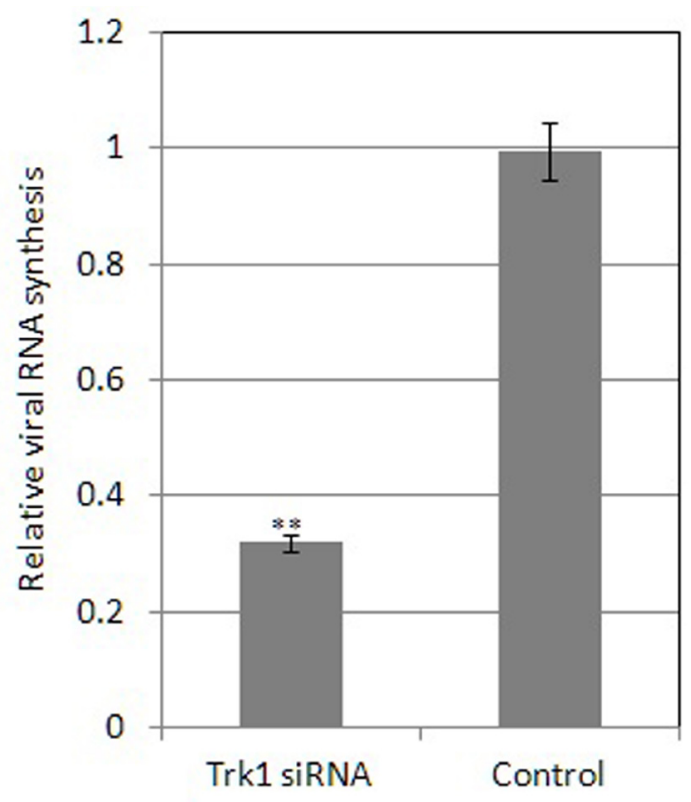

Fig. 8

Inhibition of PPRV RNA synthesis by Trk1 knockdown

Vero cells were transfected with plasmid psiRNA-hH1Trk1 expressing Trk1specific siRNA or plasmid psiRNA-hH1Luc expressing luciferase-specific siRNA (negative control), $72 \mathrm{hr}$ later infected with PPRV at MOI of 10 and at $10 \mathrm{hpi}$, cell lysates were assayed for the $\mathrm{N}$ gene mRNA. $\beta$-actin was used as a control house keeping gene for normalization. ${ }^{* *}$ represents statistical significance at $\mathrm{P}<0.01$. 
As shown in Fig. 6, at $72 \mathrm{hpt}$, psiRNAhH1-Trk1 specifically and significantly knocks down the level of Trk1 in Vero cells which was not observed with psiRNAhH1-Luc (negative control). Also, the Trk1 siRNA expressing plasmid did not affect the expression of the off-target genes, as the level of mRNA of the house keeping gene ( $\beta$-actin) was similar in both Trk1 and negative control siRNA expressing cells. At $72 \mathrm{hpt}$, when a significant knockdown of Trk1 had already occurred (Fig. 6), cells were infected with PPRV at MOI of 10 and the infectious virus released in the supernatant 10 hpi was titrated by plaque formation. As shown in Fig. 7, as compared to negative control siRNA expressing cells, there was a significant reduction in viral titers from Trk1 siRNA expressing cells. Further, a significant reduction in viral RNA was also observed in Trk1 siRNA expressing cells as compared to negative control siRNA expressing cells (Fig. 8). These findings with siRNA knockdown of Trk1 confirmed the functional role of RTK signaling in PPRV replication.

\section{Discussion}

Upon viral infections an array of signal transduction events are initiated by the host cells that are basically antiviral (Ludwig et al., 2006). However there are evidences that the virus has acquired the capability to misuse some of these signaling functions to support its effective replication (Kumar et al., 2008, 2011a). Viruses have been shown to interact with a variety of cell signaling pathways (Kumar and Maherchandani, 2014). Inhibiting such signaling activities by targeting specific host genes leads to impaired virus production suggesting their functional role in virus replication (Kumar et al., 2011b).

Recent studies have also suggested that the RTK signaling regulates replication of influenza and some other viruses (Eierhoff et al., 2010; He et al., 2010; Inubushi et al., 2008; Kumar et al., 2011a,b; Stantchev et al., 2007). Nevertheless, our previous study with influenza virus also suggested that Trk1 regulates viral RNA synthesis. (Kumar et al., 2011a). It seems, therefore, that RTK (Trk1) signaling is a prerequisite for a range of RNA viruses for efficient viral RNA synthesis. However, another study with influenza virus demonstrated that the epidermal growth factor receptor (EGFR, a RTK family member) promotes uptake of influenza $A$ viruses into host cells (Eierhoff et al., 2010) suggesting that RTKs may be involved in regulation of various steps of virus replication. It is a matter of further study to dissect the molecular mechanism of interaction between RTK and downstream signaling components to the virus counterpart.

The cellular factors that are required for the virus replication but at the same time are dispensable for the host cell metabolism may be much better target for antiviral interventions as virus can not easily replace the missing cellular functions by mutations (Kumar et al., 2008; Ludwig et al., 2006). As compared to the viral target, RTK inhibitors (a host target) have a very low tendency to develop drug resistance on sequential high passage (Kumar et al., 2011b) and hence make them more attractive target for the development of antiviral therapeutics. The antiviral strategy may not be cost effective for livestock but could complement emergency vaccination in a previously disease-free setting or be applied to treat valuable zoological collections and breeding stocks (Charleston et al., 2011; Goris et al., 2008; Kumar et al., 2014).

Taken together, it was concluded that RTK regulates PPRV replication at the level of viral RNA synthesis and hence may be proposed as a target to develop novel anti-PPRV therapeutics.

Acknowledgements. This study was supported in part by the project No. IXX08031 from CIRG, Indian Council of Agricultural Research, Makhdoom, Mathura to N. Kumar. We are grateful to the Director of CIRG for providing necessary administrative and financial support to this study. We also thank P. Malik, Incharge, Veterinary Type Culture Collection, Hisar, India for providing some cell culture reagents.

\section{References}

Charleston B, Bankowski BM, Gubbins S, Chase-Topping ME, Schley D, Howey R, Barnett PV, Gibson D, Juleff ND, Woolhouse ME (2011): Relationship between clinical signs and transmission of an infectious disease and the implications for control. Science 332, 726-729. http:// dx.doi.org/10.1126/science.1199884

Eierhoff T, Hrincius ER, Rescher U, Ludwig S, and Ehrhardt C (2010): The epidermal growth factor receptor (EGFR) promotes uptake of influenza A viruses (IAV) into host cells. PLoS Pathog. 6, e1001099. http://dx.doi. org/10.1371/journal.ppat.1001099

Gibbs EP, Taylor WP, Lawman MJ, and Bryant J (1979): Classification of peste des petits ruminants virus as the fourth member of the genus morbillivirus. Intervirology 11, 268-274. http://dx.doi.org/10.1159/000149044

Goris N, Vandenbussche F, and De Clercq K (2008): Potential of antiviral therapy and prophylaxis for controlling RNA viral infections of livestock. Antiviral Res. 78, 170-178. http://dx.doi.org/10.1016/j.antiviral.2007.10.003

He S, Ni S, Hegde S, Wang X, Sharda DR, August A, Paulson RF, and Hankey PA (2010): Activation of the N-terminally truncated form of the Stk receptor tyrosine kinase Sf-Stk by Friend virus-encoded gp55 is mediated by cysteine residues in the ecotropic domain of gp55 and the extracellular domain of Sf-Stk. J. Virol. 84, 2223-2235. http:// dx.doi.org/10.1128/JVI.02090-09

Hopfner M, Sutter AP, Huether A, Baradari V, and Scherubl H (2006): Tyrosine kinase of insulin-like growth factor receptor as target for novel treatment and prevention 
strategies of colorectal cancer. World J. Gastroenterol. $12,5635-5643$.

Inubushi S, Nagano-Fujii M, Kitayama K, Tanaka M, An C, Yokozaki $H$, Yamamura $H$, Nuriya $H$, Kohara M, Sada K, and Hotta $H$ (2008): Hepatitis C virus NS5A protein interacts with and negatively regulates the non-receptor protein tyrosine kinase Syk. J. Gen. Virol. 89, 1231-142. http:// dx.doi.org/10.1099/vir.0.83510-0

Khandelwal N, Kaur G, Singh P, Tiwari A, Singh SV, and Kumar N (2014): Silver nanoparticles impair Peste des Petits Ruminants virus replication. Virus Res. 190, 1-7. http:// dx.doi.org/10.1016/j.virusres.2014.06.011

Kumar N, Chaubey KK, Chaudhary K, Singh SV, Sharma DK, Gupta VK, Mishra AK, and Sharma S (2013): Isolation, identification and characterization of a Peste des Petits Ruminants virus from an outbreak in Nanakpur, India. J. Virol. Methods 189, 388-392. http://dx.doi.org/10.1016/j. jviromet.2013.03.002

Kumar N, Liang Y, Parslow TG, and Liang Y (2011a): Receptor tyrosine kinase inhibitors block multiple steps of influenza a virus replication. J. Virol. 85, 2818-2827. http://dx.doi. org/10.1128/JVI.01969-10

Kumar N, Sharma NR, Ly H, Parslow TG, and Liang Y (2011b): Receptor tyrosine kinase inhibitors that block replication of influenza a and other viruses. Antimicrob Agents Chemother. 55, 5553-5559. http://dx.doi.org/10.1128/ AAC.00725-11

Kumar N, Xin ZT, Liang Y, Ly H, and Liang Y (2008): NF-kappaB signaling differentially regulates influenza virus RNA synthesis. J. Virol. 82, 9880-9889. http://dx.doi.org/10.1128/ JVI.00909-08
Kumar N, Maherchandani S, Kashyap SK, Singh SV, Sharma S, Chaubey KK, and Ly H (2014): Pested des petits ruminants virus infection of small ruminants: A comprehensive review. Viruses 6, 2287-2327. http://dx.doi. org/10.3390/v6062287

Kumar N, and Maherchandani S (2014): Targeting host cell factros for development of antiviral therapeutics. Adv. Anim. Vet. Sci. 2 (1S), 37-41. http://dx.doi.org/10.14737/journal. aavs/2014/2.1s.37.41

Lemmon MA, and Schlessinger J (2010): Cell signaling by receptor tyrosine kinases. Cell 141, 1117-134. http://dx.doi. org/10.1016/j.cell.2010.06.011

Ludwig S, Pleschka S, Planz O, and Wolff T (2006): Ringing the alarm bells: signalling and apoptosis in influenza virus infected cells. Cell. Microbiol. 8, 375-386. http://dx.doi. org/10.1111/j.1462-5822.2005.00678.x

Mayer BJ (2012): Perspective: Dynamics of receptor tyrosine kinase signaling complexes. FEBS Lett. 586, 2575-279. http:// dx.doi.org/10.1016/j.febslet.2012.05.002

Shaila MS, Purushothaman V, Bhavasar D, Venugopal K, and Venkatesan RA (1989): Peste des petits ruminants of sheep in India. Vet. Rec. 125, 602.

Stantchev TS, Markovic I, Telford WG, Clouse KA, and Broder CC (2007): The tyrosine kinase inhibitor genistein blocks HIV-1 infection in primary human macrophages. Virus Res. 123, 178-189. http://dx.doi.org/10.1016/j. virusres.2006.09.004

Whitehead KA, Langer R, and Anderson DG (2009): Knocking down barriers: advances in siRNA delivery. Nat. Rev. Drug. Discov. 8, 129-138. http://dx.doi.org/10.1038/ $\underline{\operatorname{nrd} 2742}$ 